\title{
Series-parallel combined constant pressure water supply pipeline design of high-rise building
}

\author{
Li Shilei \\ Beijing Polytechnic College \\ Beijing china 100042
}

\author{
Chen Hui Wang Qiang \\ Beijing Polytechnic College \\ Beijing china 100042
}

\begin{abstract}
The existing parallel type pressurized water supply pipeline of high-rise buildings has been improved to build energy-saving high-rise building water supply systems. Series-parallel combined constant pressure water supply pipeline is designed. Antipollution high water tank is reasonably installed above the middle area of the building to supply water for the middle area high water tank and supply pressurized water by water pumps for high-rise district. And PLC control system is designed to control the work efficiency of the water pumps according to the sensor feedback information. Verified by calculation and simulation, series-parallel combined constant pressure water supply pipeline is better than parallel water supply pipes in saving the energy which is about the middle-Hybrid phase consumption of the latter. PLC control is simulated and the results show that PLC can effectively control the water supply system to ensure stable water pressure so as to save energy.
\end{abstract}

Keywords- high-rise building; water supply pipelines; series-parallel combined; PLC

\section{INTRODUCTION}

Energy is an important factor in restricting the healthy and steady development of our country's economy. Our country now vigorously promotes "energy saving and emission reduction" policy. Energy saving is the only way for the development of science and technology. Along with the constant rise of urban land price, high-rise buildings continuously gush out. How to guarantee the quality of high-rise building water supply and reduce water consumption has become a major problem the high-rise building development planning facing.

With the development of technology, the definition of high-rise building has changed gradually. In year of 1972, high-rise buildings are divided into four types. The first type is 9 to 16 floors; the second type is 17 to 25 floors; the third type is 26 to 40 floors; the fourth type is more than forty floors in international high-rise building meeting [1]. Since 2005, China regulates that residential buildings of more than ten floors and civil buildings more than 24 meters high are high-rise buildings. It is visible that high-rise buildings must use special water supply modes due to their high particularity. Early high-rise building adopts tank-type water supply methods, that is to use water pump to pump water into high water tank for the water supply. In this way, the long-term retention of water body in the tank can easily lead to water pollution. Now high-rise buildings mainly adopt frequency control pumps' constant pressure parallel water supply, which means to draw municipal pipe network's tap water into low reservoir, and then district water pumps independently uptake water from low reservoir and sent to the user by pressurization [2]. The water supply mode can prevent the secondary pollution of water supply and ensure the user's water quality, but under the condition of less water consumption, it can lead to unnecessary power consumption of water pump and pressurizer and waste a lot of energy. Based on the existing traditional frequency control pumps' constant pressure water supply way, this paper presents electric control series-parallel combined water supply way. By contrast analysis and simulation verification, this way adopts tank method which can effectively prevent secondary pollution and at the same time reasonably utilize water pump and effectively prevent the waste of energy.

\section{ENERGY CONSUMPTION ANALYSIS OF WATER SUPPLY} SYSTEM

\section{A. Pump energy consumption analysis}

High-rise buildings water supply's deliver power mainly comes from water pump with only a small part from municipal which can almost be ignored. How to save energy largely depends on how to plan a good pump power utilization. Now pump energy consumption is analyzed.

Pump's instantaneous shaft power is:

$$
N=K \frac{N_{0}}{\eta}=K \frac{\lambda Q H}{100 \eta_{1} \eta_{2}}
$$

In formula (1), $N_{0}$ is the maximum shaft power of water pump in normal work and its unit is $\mathrm{kw} ;{ }^{2}$ is transmission efficiency (\%); $Q$ is output flow of water pump in the maximum shaft power work, and the unit is $m^{3} / h$; $H$ is the water pump lift in the largest shaft power work, and the unit is $m ; \eta_{1}$ is the work efficiency of water pump in the 
largest shaft power work(\%); $\lambda$ is water density, and the unit is $N / \mathrm{m}^{3} ; \mathrm{K}$ is the motor reserve coefficient.

Because of the constant changes of lift and flow, water power changes constantly. By using calculus, the average hydraulic power $P$ of the water pump for the time moment during 0 to 1 is:

$$
P=\frac{1}{t} \int_{0}^{t} \rho g Q H d t=m \rho g H
$$

The average power $P$ in the given time is relevant to the corresponding lift $H$ in unit time and internal water flow $Q$,s variation law $m$ with time. When $m$ is taken set value, the given pump instantaneous lift $H$ is bigger and the instantaneous energy consumption of water pump is greater.

\section{B. Pipeline energy consumption analysis}

Pipeline produces water flow resistance, and reasonable piping layout can effectively reduce pipeline flow resistance and at the same time can reduce pump working resistance. It can be said that the optimization of pipeline saves considerable energy for high water supply system.

Each parameter of pipeline liquid flow follows Bernoulli equation. Combined with Figure 1, the Bernoulli equation of total fluid flow is

$$
z+\frac{p}{\rho g}+\frac{\alpha v^{2}}{2 g}=\left(z_{1}+\frac{p_{1}}{\rho g}+\frac{\alpha_{1} v_{1}^{2}}{2 g}\right)+\left(z_{2}+\frac{p_{2}}{\rho g}+\frac{\alpha_{2} v_{2}^{2}}{2 g}\right)
$$

Figure 1. Parallel pipeline cross-section diagram

$p_{1}, p_{2}$ and $p$ are respectively the pressure of section 1,2 and $3 ; \alpha, \alpha_{1}$ and $\alpha_{2}$ are kinetic energy correction coefficient of section 1, 2 and 3; $v, v_{1}$ and $v_{2}$ are water flow rate of section 1,2 and 3 and the unit is $\mathrm{m} / \mathrm{s}$;
$Z,{ }^{Z}{ }_{1}$ and ${ }^{Z}$ are the height of section 1,2 and 3 , and the unit is $m$. Assume pipeline diameter $d=D$, from Formula(3) it can be got:

$p=p_{1}+p_{2}+\frac{16 \rho Q_{2}\left(Q-Q_{2}\right)}{\pi^{2} D^{2}}-h_{1} \rho g$

From Formula(4), it is known that the pressure after fusion of two water areas in parallel place is not equal to the sum of the original two separate flow liquid pressure. It will produce a certain energy loss. If the loss item is $H_{L}$, combining with Bernoulli formula,

$H_{L}=\frac{p}{\rho g}=\frac{p_{1}+p_{2}}{\rho g}+\frac{16 Q_{2}\left(Q-Q_{2}\right)}{\pi^{2} D^{4} g}$

According to the size of the loss item, the efficiency in parallel place is

$\eta=1-\frac{H_{L}}{H}=1-\left(\frac{p_{1}+p_{2}}{\rho H g}+\frac{16 Q_{2}\left(Q-Q_{2}\right)}{H \pi^{2} D^{4} g}\right)$

Effectively control the loss item can improve pipeline water transport efficiency so as to save energy. And the improvement of pipeline efficiency can effectively reduce the flow resistance and it is a kind of protection mechanism for water pump.

\section{SERIES-PARALLEL COMBINED WATER SUPPLY} PIPELINE DESIGN

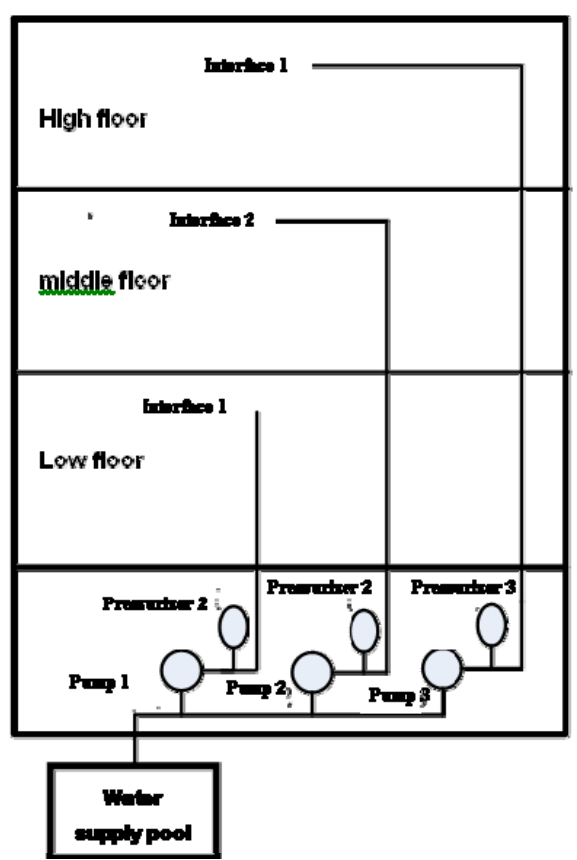

Figure 2. Parallel water supply pipeline

Nowadays most high-rise buildings use parallel water supply pipelines, which draw the municipal water supply into underground reservoir. By using the independent work 
of low, medium and high three kinds of water pump, water is extracted and supply water to top area, middle area and lower area through the three different pressurizers, which is shown in Figure 2.

The advantages of parallel water supply pipeline are: water supply pipeline has not set tank. Pumps are centered in the buildings' bottom water pump room, which not only reduces the floor noise, improves the buildings' life, and saves the efficient use of the high-rise building; Equipment pumps are centralized in the basement, which facilitates the united maintenance and management of the water pump.

Parallel water supply pipelines' defects are: water pumps are of different types which consumes construction cost, and at the same time the maintenance costs are also bigger; top area's water supply pump power and lift are very big, which needs power supply of high tension lines. When building height is high, low space pressure of water supply pipeline is particularly big, so it needs more steel and high cost, and easy to appear leakage; At the same time the pump power variation of this kind of structure is bigger which leads to the big change rangeability of the hydraulic pressure and easy to arise water pump and pressurizer failures [3]; The most important thing is that this kind of structure mode is influenced by water peak period and low period, which cannot effectively regulate the water pressure and water supply, which would lead to the idle phenomenon of the pump, and pressurizer's empty running state. This would not only reduce the system life, but produce a large amount of energy wast [4].

According to the shortages of parallel water supply pipeline, the high-rise water supply line is improved in order to save energy resources.

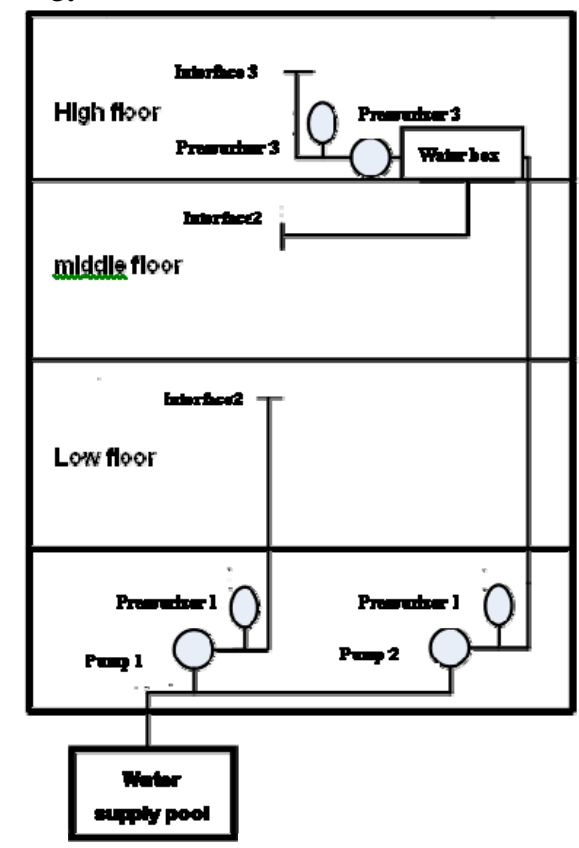

Figure 3. Series-parallel combined water supply pipeline
As is shown in Figure 3, the parallel system of water supply line is improved. The water supply mode in lower area remains the same by using the combination of pump and pressurizer. The 2 pump line end is improved by setting a tank in the high place of middle area. The water tank has two pipelines, one to supply water for the middle area, the other supply water for top area through the combination of low power pump and pressurizer. We call this kind of water supply pipeline the series-parallel combined water supply pipeline.

In order to prevent the secondary pollution of water tank, water tank uses high polished stainless steel inner layer to effectively prevent water tank rust and microorganisms and bacteria group hunging. Water tank supplies water for the middle area and top area at the same time, and the water flow is bigger. Also it effectively prevents water retention and avoids the secondary pollution.

Of course, compare with parallel water supply line, series-parallel combined water supply pipeline has better energy saving effect. Consider the last term of Formula(6)alone, and set it $\eta_{\mathrm{g}}$,

$$
\eta_{\mathrm{g}}=\frac{16 Q_{2}\left(Q-Q_{2}\right)}{H \pi^{2} D^{4} g}
$$

The bigger $\eta_{\mathrm{g}}$ is, the higher the efficiency of the whole pipeline operation. From Formula(7), it can be seen that selecting the right $Q_{2}$ can enhance efficiency and $Q_{2}$ determines the height of the water tank. According to Formula(7), the relationship between the efficiency and tank installation positions of 23 storeys high-rise building(each layer $3 \mathrm{~m}$ ) is simulated.

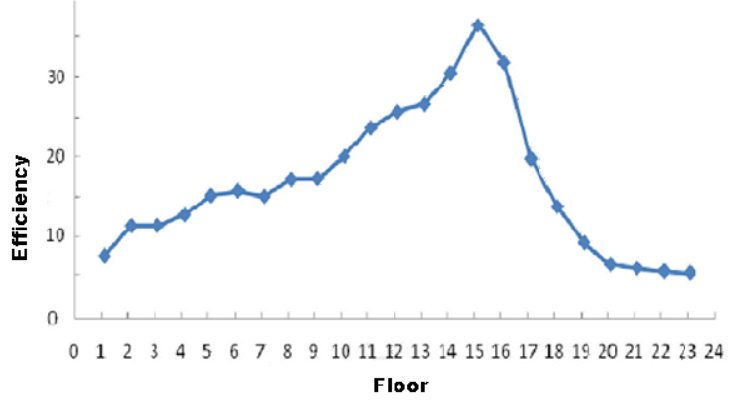

Figure 4. The relationship between height of tank installation and efficiency

Through Figure 4, it can be seen that the tank is the most efficient when it is located in 16 floor, which also conforms to the tank design of series-parallel combined water supply pipeline.

When water pressure is the same in top area and lift $\mathrm{H}_{3}$ is the same, then

$$
P_{1}^{\prime}=P_{1}
$$




$$
P_{3}=P_{2}{ }^{\prime}+P_{3}^{\prime}
$$

$P_{1}$ is the working efficiency of pump 1 before the improvement. $P_{3}$ is the working efficiency of pump 3 before the improvement. $P_{1}^{\prime}$ is the working efficiency of pump1 after the improvement. $P_{2}{ }^{\prime}$ is the working efficiency of pump 2 after the improvement. $P_{3}^{\prime}$ is the working efficiency of pump3. After the improvement, the hydraulic pressure of the middle period is reduced, but energy saved is almost the power of pump 2 before the improvement. It can be said that the power is very considerable.

\section{PLC CONTROL SYSTEM DESIGN}

Water pump rotational speed control has close relationship with energy saving, cost reducing and the economic benefits improvement. There are many kinds of pumps in series-parallel combined water supply pipeline and more powerful. To prevent pump idle and save energy, PLC is used to change frequency so as to change water pump's motor speed.

The principle of changing the frequency to change water pump's motor speed is based on the following formula:

$$
n=\frac{120 f}{P(1-s)}
$$

$n$ is water pump speed; $f$ is power frequency; $P$ is motor pole; $S$ is slip ratio. From the above formula, power supply frequency $f$ which can smoothly change motor stator can smoothly change motor synchronous speed. In order to keep the peak torque stability of motor in the changing process, motor's magnetic flux should be stable, which requires corresponding adjustment of stator supply voltage. So the transducer set here has frequency modulation and pressure regulating two functions [5].

In theory, flow $Q$ is directly proportional to the first power of speed $n$; lift $H$ is directly proportional to the second power of speed $n$; power $N$ is directly proportional to the third power of speed $n$.

$$
\begin{aligned}
& \frac{H_{2}}{H_{1}}=\left(\frac{Q_{2}}{Q_{1}}\right)^{2} \\
& \frac{N_{2}}{N_{1}}=\left(\frac{Q_{2}}{Q_{1}}\right)^{3}
\end{aligned}
$$

Lift $H$ is directly proportional to the second power of flow rate $Q$; power $N$ is directly proportional to the third power of flow rate $Q$. In theory, a small change in the flow can cause significant change of lift and power.

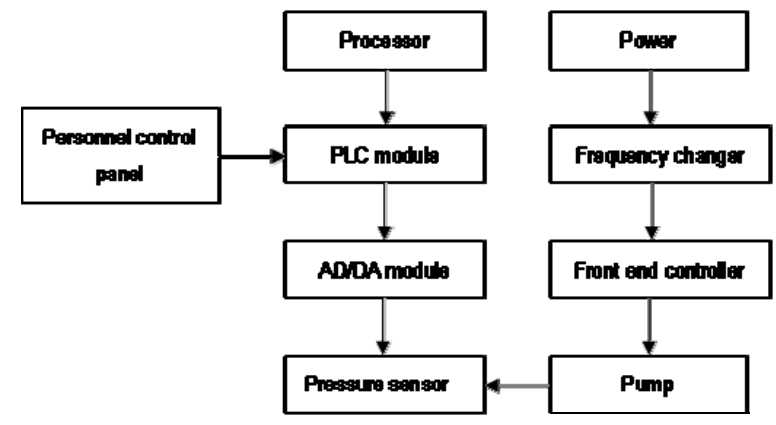

Figure 5. PLC control ideograph

As is shown in Figure 5, pressure sensor is set to monitor pump operation state. The signal is sent to PLC controller by conversion module and at the same time feedback control information. The voltage is controlled to achieve the pump operation under the designated power through adjusting front controller and frequency converter.

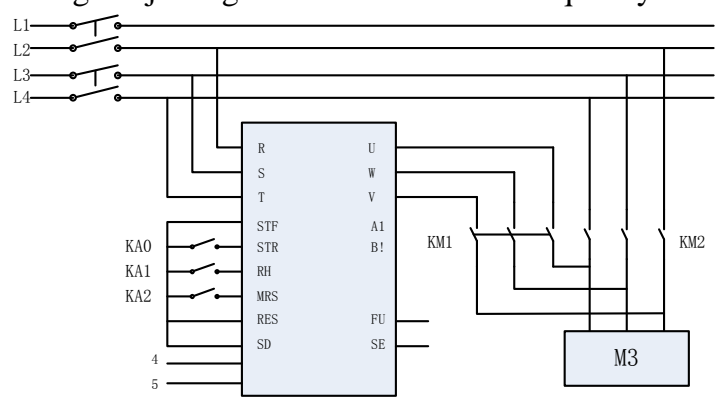

Figure 6. Control system circuit diagram

The main circuit of constant pressure water supply control system is in Figure 6. The system adopts the way of 1 controlling 1. Switches KM1 and KM2 can control the frequency operation and variable-frequency operation of M3. Frequency converter adopts forward start and operation mode. Interface terminals 4 and 5 are used to connect with PLC output electrical signals.

When water consumption increases, pump 2's speed achieves rated value $(50 \mathrm{~Hz})$. If the water consumption increases further, the system automatically switches pump 3 to the power grid and at the same time use the frequency converter to regulate pump 2 until hydraulic is stably set in the set pressure value [6]. When water consumption decreases, and pump 2 operates to the lower limit frequency, pump 2 automatically stops. Pump 1 and 3 automatically adjust the water pressure continually through the converter. If the water consumption increases, pump 2's speed achieves the rated value. The system improves the power frequency of pump 2 and control pump 3's operation through frequency converter [6]. The automatic constant pressure water supply can be achieved through continuous cycling. 


\section{SERIES-PARALLEL COMBINED CONSTANT PRESSURE WATER SUPPLY PIPELINE SIMULATION}

The control panel: WinccFlexible touch screen of Siemens is used to perform element condition monitoring, action state monitoring, PLC diagnosis, switch change, serial communication, online modification parameter, and display water pressure, water level, and frequency parameters.

PLC: Siemens SIMATIC S7-300 PLC is used and at the same time boundled software STEP7 V5.5 is selected. The voltage is checked through the upper WinCC software and oscillograph is produced.

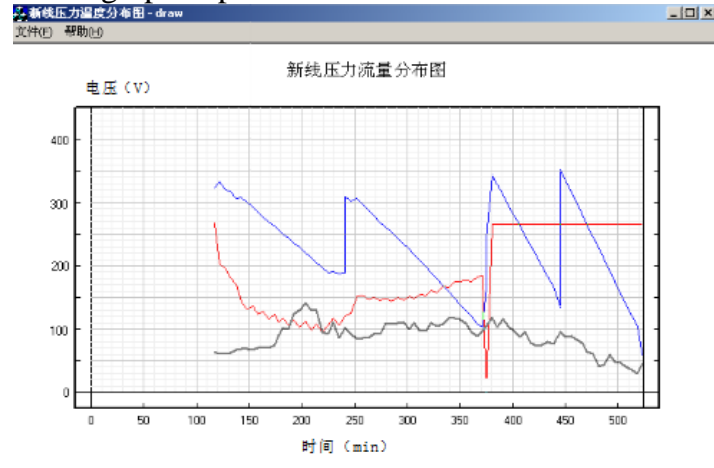

Figure 7. STEP7 Wincc simulation results diagram

In STEP7 Wincc simulation, PLC control voltage changes and adjusts with sensor feedback information. Pump operating voltage is agile and reliable in the PLC control voltage. It is verified that PLC can effectively monitor pipe pressure and pump pressure and control pump operation through feedback.

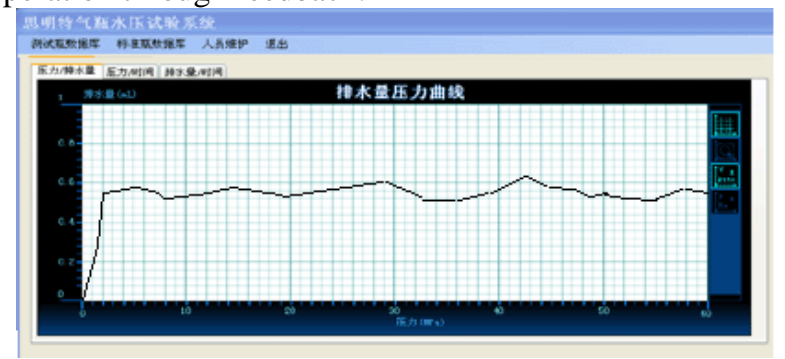

Figure 8. pipeline pressure curve in middle area

As is shown in Figure 8, it is found that pipeline pressure quickly gets to the specified working pressure by monitoring the middle pipeline pressure after starting, and keeps smooth. The pressure difference is not more than 0.05
Mpa, which shows that PLC system can effectively control the water pressure and keep it stable.

\section{SUMMARY AND PROSPECT}

This paper improves high-level parallel water supply pipeline and designs series-parallel combined water supply pipeline. By comparison, energy saving target can be realized. And PLC automatic control system design may adjust water pumps so as to achieve constant pressure and save the energy. The simulation results show the feasibility of the system design and can guarantee pipeline's constant pressure.

The energy saving space of water supply line in the paper is still large. Pressure-relief devices can be designed and configurate different pressures for different water sites demanded to prevent the waste of water resources caused by water overvoltage. And the PLC system is still not perfect, we can design many sensors to monitor the water tank and pipeline everywhere. A more comprehensive integrated feedback information is used to control water pump. Solving these problems can make the high-rise building's water supply more effective. We will work constantly to improve water supply system in the future.

\section{REFERENCES}

[1] Conehilla,Miehael:Krarti,Moneef.Interaetions of water and energy use in resid-ential buildings, Partl : Modeling . ASHRAE Transaetions. 2002,108(l):283 293

[2] The second research institute of nuclear industry ministry, water supply and drainage design manual book 2 [M]. Beijing: China Architecture \& Building Press, 198.

[3] Datta RSN,Sridharan K.Paramete restimation in water distribution systems.Journal of Water resource Planing and Management , 1994,120(4):405-422

[4] Yang WenLing, Wang ChunYan. The development of building water supply and drainage design and problems need to be solved [J]. Journal of Chongqing Architecture University. 1998, 16 (5) : 88-9

[5] Zhang LiHui. The research and design of fuzzy controlled frequency control of motor speed constant pressure water supply system [D]. Changchun: Jilin University, 2007.

[6] Shen GuiYing, Sun Bin, Ma Guang. Fuzzy control of constant pressure water supply system [J]. Industrial Instrumentation and Automation Equipment, 2002 (5) : $-52$.

[7] Yu JingYang. Water supply network hydraulic dynamic simulation [D]. Hefei: Hefei University of Technology, 2006 